\title{
THE DECISION TO MAJOR IN INFORMATION SYSTEMS: CRITICAL FACTORS FOR STUDENTS
}

\author{
Douglas Havelka, Miami University, havelkdj@miamioh.edu \\ Jeffrey W. Merhout, Miami University, merhoujw@miamioh.edu
}

\begin{abstract}
Throughout the United States, there seems to be a perpetual need to attract more business students in colleges and universities to major in information systems. Thus, a study was conducted using a focus group of graduating students from a large Midwestern US university's information systems program. The focus group identified factors that influenced their choice to major in information systems, and the factors deemed critical were then ranked by the students and subsequently classified by the researchers into categories for further analyses. Results reveal that new and exciting career opportunities is the number one reason that these students chose to major in information systems and that the female and male panelists just about equally listed this category as the critical reason for their choice. The categories can form a framework for further study of factors influencing students' decision to study information systems and then choose a career in information technology.
\end{abstract}

Keywords: Career Choices, Structured Group Technique, Group Data Collection, IT Careers, IS Majors, Student Recruitment

\section{INTRODUCTION}

Unlike with some of the other business school major offerings, students do not often come into a university with the intention to major in information systems (IS) or other majors with similar names. Accounting, finance, marketing, and economics seem to have plenty of first year students in their majors, but very few in the first year class choose information systems right out of high school. For example, in recent years, less than $1 \%$ of the annual incoming Farmer School of Business first-year classes at Miami University are declared information systems and analytics majors.

Thus, faculty in information systems departments typically have to work hard to attract students into their major in order to have enough of a critical mass to be a viable department within the business school. Our study seeks to identify factors that influence students decision to major in information system in order to be able to use that information to better market to future first and second-year students in order to the get more of them to select information systems as a possible major. In prior research, we used a focus group of eight graduating seniors with IS majors from our Midwestern US university program to elicit a lengthy set of factors that the students said influenced their decision and then had them rank which ones they deemed were critical to that choice.

The purpose of this second round of focus groups we have conducted is to help address the shortage of information technology (IT) workers in the United States by investigating the considerations that influenced our university's alumni to study information systems and thus choose a career in (IT). This study addresses numerous calls for research that seeks ways to encourage more students to major in IS or IT (e.g., Benamati \& Rajkumar, 2013; Riemenschneider et al., 2009; Trauth, 2012; Trauth, Quesenberry, \& Huang, 2009). In the discussion that follows, we review the research method we used to collect the data and then we describe how we analyzed the results by developing an overall ranking of factors deemed critical. We then categorize these factors and develop a model of antecedents of these students' decision to major in IS. Thereafter we discuss some possible weaknesses of our research and conclude by making recommendations for using our results to inform IS program efforts to attract and retain more IS majors as well as suggestions for future research.

\section{RESEARCH METHOD}

To identify and evaluate factors that impact a student's selection of IS as a major, we used a modified structured group process. This approach relies on the notion that individuals who perform a task or make a decision can provide information that influenced their behavior or decision. This group data gathering approach has been used in this domain and in others when the goal is to elicit a comprehensive (although not exhaustive) set of factors for a 
given problem or decision. In a prior related study, focus groups of recently graduated alumni (with IS majors) were used to explore why they chose an IS major (Merhout, Havelka, and Rajkumar, 2016). In a 2009 study, the structured group process was used to gather data identifying key skills and abilities that employers of IS majors were seeking when hiring entry-level IS talent (Havelka and Merhout, 2009). Another study in this domain using a similar data gathering method focused on the factors influencing females to choose a major in computer information systems (Mishra et al. 2014). Some of the other domains where this technique has been used includes: systems development (Havelka 2003; Havelka, Sutton \& Arnold, 1998), auditing (Duggan \& Thachenkary 2004; Sutton \& Lampe, 1991), and in IT audit quality (Havelka \& Merhout, 2009; Merhout \& Havelka, 2008).

When the objective of a data gathering activity is the generation of a comprehensive set of facts or ideas; structured processes have been found to as good as, or better than, other data gathering approaches. When the desired outcome is a maximum number of ideas or alternatives, the group approach can be superior because it allows participants to build on others ideas (Tremblay, Hevner, \& Berndt, 2010). Moreover, the ideal size of these groups is around six to nine participants in order to allow each person an ample opportunity to be heard.

Table 1. Structured Group Technique Used

\begin{tabular}{|c|l|}
\hline Step 1: & $\begin{array}{l}\text { The facilitators requested general introductions by the participants, explained the purpose } \\
\text { of the study and the meeting, explained the nominal group process to be performed, and } \\
\text { introduced the research question to be answered by the subjects. The question specifically } \\
\text { posed to the group was stated as: } \\
\text { "What factors influenced your decision to study IS and pursue a career in IT?" }\end{array}$ \\
\hline Step 2: & $\begin{array}{l}\text { Each subject was then asked to quietly generate as many of these factors as possible on a } \\
\text { worksheet that each individual was provided. }\end{array}$ \\
\hline Step 3: & $\begin{array}{l}\text { After about ten minutes the facilitators began to write the indicators on flipcharts for all } \\
\text { the participants to view. The factors were elicited from the participants in a sequential } \\
\text { fashion until all the participants' lists had been exhausted. Only questions related to } \\
\text { clarifying the indicators being listed were allowed at this point and no discussion of the } \\
\text { merits or importance of the determinant was permitted. The participants were encouraged } \\
\text { to add to their lists as this step progressed. }\end{array}$ \\
\hline Step 4: & $\begin{array}{l}\text { After all of the factors were listed, discussion for clarification of the items and distinction } \\
\text { from one another was encouraged. Again, discussion of the relative merits or importance } \\
\text { of the indicators was discouraged. }\end{array}$ \\
\hline Step 5: & $\begin{array}{l}\text { Each focus group member was then asked to identify (on a worksheet) those antecedents } \\
\text { generated by the entire group that they, as individuals, considered "critical” to their } \\
\text { decision to study Information Systems. The number of these critical factors was up to the } \\
\text { individual participant. }\end{array}$ \\
\hline Step 6: & $\begin{array}{l}\text { The participants were then asked to rank the factors that they identified in step 5 from } \\
\text { most important to least important. }\end{array}$ \\
\hline Step 7: & $\begin{array}{l}\text { The participants were also asked to fill out a questionnaire for demographic data and their } \\
\text { time and participation were acknowledged. }\end{array}$ \\
\hline
\end{tabular}

As mentioned above, the validity of this approach is based on the fact that individuals who have had direct experience with a specific task or decision has the ability to identify the critical factors that influence or impact the task or decision. Therefore, it is crucial to identify and recruit only participants that have relevant experience with the problem domain. The data gathering technique consists of a series of activities performed by a group of selected participants. The activities include group brainstorming, clarification, and evaluation techniques. The output of the data gathering process is a large set of "indicators" that can then be evaluated and analyzed to determine relative importance among the indicators. These indicators can also be used for a qualitative analysis to determine higher 
level factors and categories for further study (including potential relationships among the factors or differences among sub-populations of students, i.e. gender).

For this project, we identified a set of graduating seniors that were IS majors. This group was asked to identify the factors that influenced their decision to study IS. Further analyses of the categories' and factors' influence on students' decision to study IS can be conducted based on the outcomes of this and additional group sessions. The specific structured group process used in this study is based on prior research (Merhout et al., 2016) and the step-bystep details of the technique are summarized in Table 1.

\section{DATA COLLECTION AND RESULTS}

This paper only includes the data gathered from our focus group with our students, all of whom were upperclassmen and all of whom had accepted job offers at the time of the data gathering. Table 2 presents a brief overview of their accepted first career position. These students are representative in the sense that the list of accepted positions reflects the diversity of opportunities that our IS graduates have today. This diversity was one consideration when we recruited the student participants. We also considered the fact that these students had recently (compared to alumni) made the decision to study IS, so we felt that the considerations that they had included in their major decision making were still relatively fresh in their minds.

Table 2. Focus Group Demographics - Initial Career Path

\begin{tabular}{|c|l|}
\hline Gender & Accepted Position \\
\hline Female & Consultant, Data Security and SAP Risk Management \\
\hline Female & Consultant, Technology Side of the Internal Audit and Financial Advisory \\
\hline Female & Junior Software Engineer \\
\hline Female & Associate in IT Audit and Attestation \\
\hline Male & Information Technology Leadership Development Program \\
\hline Male & IT Advisory Associate \\
\hline Male & Digital Technology Leadership Program \\
\hline Male & Cyber Security \& Privacy Associate in public accounting \\
\hline
\end{tabular}

The overall results from the data gathering process is presented in Table 3. A total of 66 factors were identified by this group. The outputs are also given by gender where possible. Although we cannot make any statistically valid conclusions based on eight participants, we can make some observations related to the results based on gender. The male participants identified a higher number of factors overall compared to the females during the data gathering (41 versus 25). However, the number of factors identified as "critical" by male versus female participants was nearly the same 30 versus 28). Given that the total number of factors identified as critical (i.e. the total number of unique factors identified by either males or females) was 39 implies that there was a difference in the factors identified as critical by the two genders.

To assess the relative importance of the factors identified by the group, we use the rankings obtained from Step 6 of the data gathering process. Using the rankings of the factors by each individual, we calculate a score for each factor identified. The score is calculated by assigning the top-ranked factor of each individual the value of the total number of factors identified. In this case there were 66 factors identified; so each participants' top-ranked factor is given a value of 66 . The factor ranked \#2 for each participant is then given the value equal to the total minus one (66-1=65), and so on for each lower ranked factor. This is done for all the factors ranked by each participant. Any factors that were considered non-critical by a participant were scored as zero when determining the sums. This approach gives an overall ranked list of all the factors considered critical. The top 12 factors, which were considered critical by at least three of the participants, are given in Table 4. 
Table 3. Overall Results of Focus Group

\begin{tabular}{|r|c|c|c|}
\hline & Total & Female & Male \\
\hline Number of participants in the group: & 8 & 4 & 4 \\
\hline Total number of factors identified: & 66 & 25 & 41 \\
\hline Number of factors selected as critical (of group total): & 39 & 28 & 30 \\
\hline Percentage of factors selected as critical (of group total): & 59 & 42 & 45 \\
\hline Number of factors considered not critical: & 27 & 38 & 36 \\
\hline $\begin{array}{r}\text { Number of factors considered critical by <= 2 panelists and thus not } \\
\text { included in categorization analysis below: }\end{array}$ & 27 & 16 & 19 \\
\hline
\end{tabular}

Based on the scores calculated, it would appear that the most important factors to our participants were based on the financial and other practical benefits associated with a major/job that is in high demand. Five of the top six factors are directly related to these benefits: 1) career opportunities, 2) earning potential, 3) job security, 5) high job demand, and 6) want to earn money. In addition, two of the remaining top 12 could also be considered related to these benefits: 7) growing field and 10) skills becoming more valuable.

Table 4. Top Factors (based on ranking scores)

\begin{tabular}{|ll|c|c|c|}
\hline Critical Factor & Total & Female & Male \\
\hline 1. & Exciting and new career opportunities & 369 & 179 & 190 \\
\hline 2. & Earning potential for just a BS degree & 319 & 253 & 66 \\
\hline 3. & Job security & 318 & 252 & 66 \\
\hline 4. & Good balance of business and technology & 314 & 126 & 188 \\
\hline 5. & High job demand & 310 & 132 & 178 \\
\hline 6. & Want to earn money & 244 & 55 & 189 \\
\hline 7. & Part of a growing field & 193 & 127 & 66 \\
\hline 8. & Preference for hard skills (versus soft) & 188 & 188 & 0 \\
\hline 9. $\quad$ More social interaction (versus strictly IT) & 174 & 116 & 58 \\
\hline 10. & Skills becoming more valuable & 173 & 54 & 119 \\
\hline 11. & Millennial friendly & 172 & 111 & 61 \\
\hline 12. & Interaction between diverse personalities & 172 & 114 & 58 \\
\hline
\end{tabular}

In addition to the benefits of a job in IT, there appears to be a theme suggesting that some of our participants chose IS instead of computer science or engineering. Three of the factors in the top 12 recognize the non-technical aspects of IS: 4) balance of business and technology, 9) social interaction, and 12) interaction between diverse personalities. In opposition to this theme, however, is factor \#8 Preference for hard skills. This would imply that some of the participants have a preference for more technical content. This may be an intellectual interest, enjoyment from use, or just a recognition of the value of more technical topics. The fact that only the female participants considered this factor critical may require further exploration. 
Another theme that could be extracted from the results is a "generational" dimension. Several of the factors seem to recognize the ubiquity and importance of technology in the economy and modern life: 7) growing field, 9) social interaction, and 11) millennial friendly. Factor \#12, interaction between diverse personalities, may also reflect this perspective.

Based on the outputs of the group, there appears to be some difference in the determination of which factors are critical and the relative importance of these factors (based on the ranking scores) between genders. This may suggest that the considerations to pursue careers in information technology vary between the sexes. This should have implications for IS programs recruiting efforts and for further research in this domain.

\section{ANALYSIS OF FACTORS}

To further expound on the results of the group data, we have created a preliminary model of the IS major decision. To create this model we (the authors) independently created categories and logically assigned each factor to one of the categories based on our professional experiences and judgment. Discrepancies between the results were discussed and resolved among us. The resulting model consisted of five categories of factors as presented in Table 5 and described below.

Table 5. Logical Categories of Factors

\begin{tabular}{|l|l|}
\hline \multicolumn{1}{|c|}{ Category } & \multicolumn{1}{c|}{ Example Factors } \\
\hline Career Opportunities/Potential & $\begin{array}{l}\text { Exciting and new career opportunities } \\
\text { Earning potential for just a BS degree } \\
\text { Job security }\end{array}$ \\
\hline Type of Work & $\begin{array}{l}\text { Good balance of business and technology } \\
\text { Preference for hard skills (versus soft) } \\
\text { Allows for constant learning (constant change) }\end{array}$ \\
\hline Work Culture & $\begin{array}{l}\text { More social interaction (versus strictly IT) } \\
\text { Millennial friendly } \\
\text { Interaction between diverse personalities }\end{array}$ \\
\hline Importance/Relevance of Field & $\begin{array}{l}\text { Expanding role on other disciplines/areas } \\
\text { Relevant to today's world issues (hacking, ISIS) } \\
\text { Ability for organizational impact }\end{array}$ \\
\hline Influencers & $\begin{array}{l}\text { Parents are in related field, such as computing } \\
\text { Early exposure in high school } \\
\text { Enjoyed content in required core class with hands-on } \\
\text { focus on skills, such as Excel and database }\end{array}$ \\
\hline
\end{tabular}

\section{Career Opportunities/Potential}

The first category we created was the Career Opportunities/Potential category. This category would include all of the factors related to the job market and potential for future increases in earning power and career advancement. As mentioned earlier, factors in this category were evaluated as the most important by our group. This category is clearly related to the demand and supply of individuals with IS knowledge and skills. This marketplace is affected 
by many external forces including the general economy, the number of students studying IS/IT, and potentially the use of AI (artificial intelligence) to perform some of the activities currently performed by humans.

\section{Type of Work}

The second category is the Type of Work. This reflects the challenging and constantly changing skills required to be a successful IS professional. This would include the need for the ability to understand technical material and to the ability to apply this knowledge to business problems. We believe this captures the "blended" nature of most IS positions versus computer science or engineering. Students select IS because it has a technical aspect, but is not focused on technology.

\section{Work Culture}

The third category is the Work Culture. This refers to the environment that most IS professionals work in today. This could be related to the second category, but includes factors that are not directly related to work activities. Most of the employers that recruit our students have adopted what could be considered "employee-friendly" work places. Some of these firms have adopted the "Agile" approach to development and other IT functions.

\section{Importance/Relevance of Field}

The fourth category identified is the Importance/Relevance of the Field. This category includes the factors that reflect the importance and ubiquity of information technology in modern life and business. Our students have grown up surrounded by technology and it would seem that those who recognize this and value it may select an IS major over another.

\section{Influencers}

The last category we identified is Influencers. This refers to individuals that have promoted or introduced the field of IS to our students. This could include parents or other relatives, high school teachers or counselors, employers, and instructors at the university. This could also include experiences prior to selecting a major, such as a course or work experience that was rewarding.

We believe that this simple "taxonomy" or model of the factors captures all of the factors identified by our group. However, we recognize that there could easily be other factors that do not fall in these categories; so we propose this as preliminary model.

\section{DISCUSSION, FUTURE RESEARCH, AND CONCLUSION}

The factors identified by the groups and the categories suggested above form a model that could be used for further study of the student decision to study IS. An overview of the model is presented in Figure 1. The model could be used for multiple purposes by different stakeholders to the selection of IS as a major. First and foremost, the model could be helpful to administrators, faculty, and employers that are working to increase IS enrollments. By focusing on some of the key factors, we may be able to influence more students to study IS. This model could also be used educators lower levels, including middle school and high school, to create or refine programs that would provide rewarding experiences to students interested in IT.

Our results are consistent with other research in this area. Snyder and Slauson (2014) found that their students were motivated by both personal interests and employment opportunities to major in IT related fields. Additional research is needed to further understand the various factors and whether specific programs or initiatives might increase enrollments. Additional research to compare and contrast results from other institutions and settings would be valuable. 


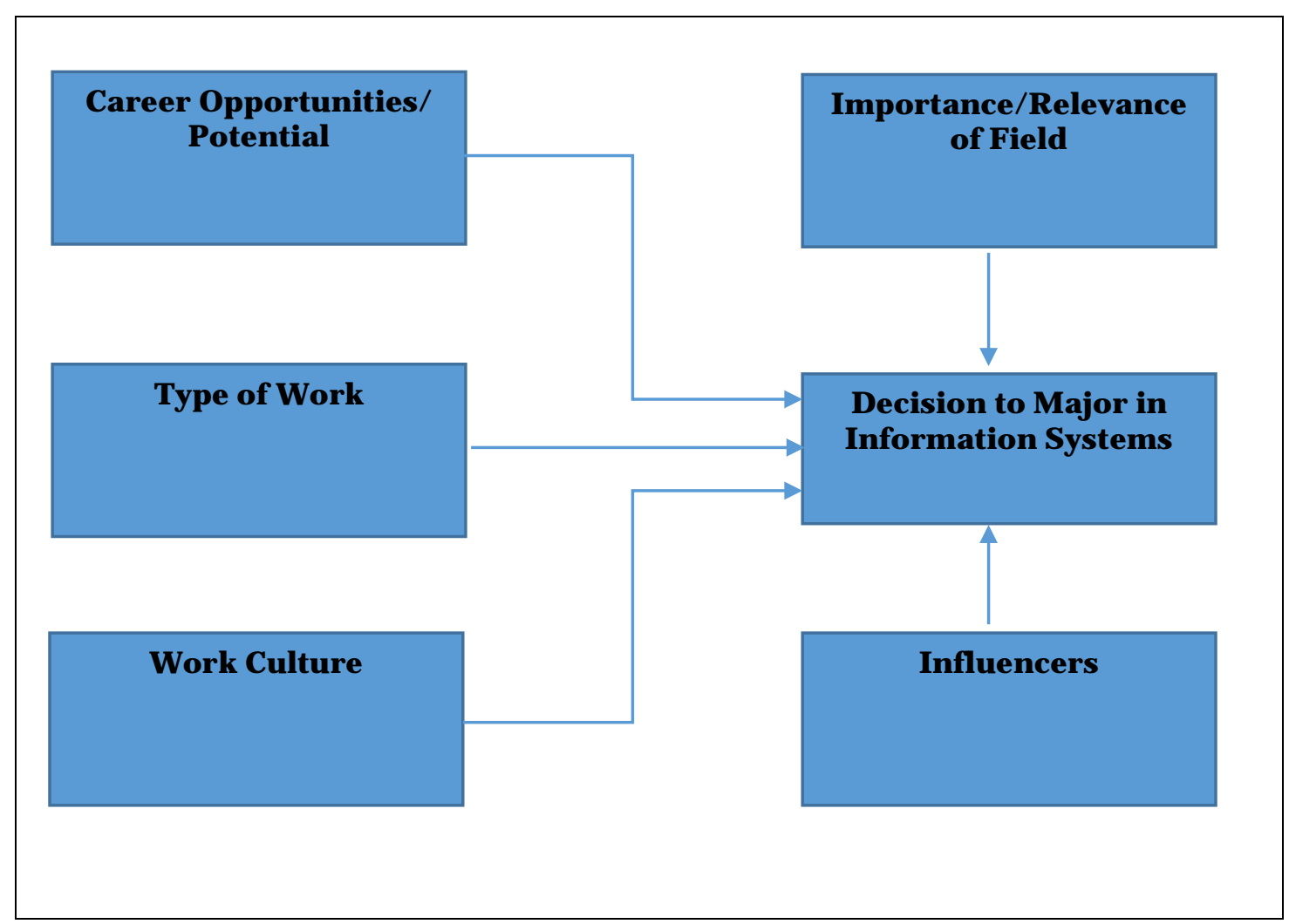

Figure 1. A Model of Drivers of Students Decision to Major in IS

Clearly, this type of research is exploratory in nature and we recognize that there are several weaknesses and drawbacks that should be acknowledged. First, the fact that the data is generated by one small group of students from the same university and they grew up in the same region of the country severely limits the generalizability of our results. Furthermore, they are not very diverse; ethnically or otherwise. In addition, we allowed the group to generate all the factors without regard to prior research or trade publications. These sources may have provided additional context for the group to consider.

The results of this group data collection technique includes a set of factors that may impact the decision to major in IS, an evaluation of the importance of these factors relative to one another, and the creation of a higher level model that aids in understanding the decision. We suggest that these results should inform IS programs efforts to attract and retain more IS majors. We believe additional research with other stakeholders or students with a more diverse set of backgrounds would also help to develop a more comprehensive set of factors and improve our results.

We believe that this "scholarship of teaching" is valuable to several stakeholders: our IS programs, employers, and society in general. Our programs should benefit by increasing enrollments and demand for our courses (this should also benefit the college and university). By increasing enrollments we would be able to provide more graduates for our employers to hire. And we hope that society in general would benefit from tech-savvy business professionals. Lastly, we think by recruiting more individuals to our field their lives may improve due to the benefits of a career in IT. 


\section{REFERENCES}

Benamati, J. H. and Rajkumar, T.M. 2013. "Undergraduate Student Attitudes Toward MIS: Instrument Development and Changing Perceptions of the Field Across Gender and Time," Communications of the Association for Information Systems: Vol. 33, Article 14. Available at: http://aisel.aisnet.org/cais/vol33/iss1/14

Duggan, E.W., and Thachenkary, C.S. 2004. "Integrating nominal group technique and joint application development for improved systems requirements determination," Information \& Management (41), pp. 399411.

Havelka, D. 2003. "A user-oriented model of factors that affect information requirements determination process quality," Information Resources Management Journal (16:4), Oct-Dec 2003, pp. 15-32.

Havelka, D. and Merhout, J. W. 2009. "Toward A Theory of Information Technology Professional Competence," Journal of Computer Information Systems, Winter 2009-2010, Vol. 50, Issue 2, pp. 106-116.

Havelka, D., Sutton, S.G., and Arnold, V. 1998. "A methodology for developing measurement criteria for assurance services: An application in information systems assurance," Auditing: A Journal of Practice \& Theory (17: Supplement), pp. 73-92.

Mishra, S., Draus, P., Caputo, D., Leone, G., Kohan, F. and Repack, D. 2014. "Gender Rationales in Selecting a Major in Information Technology at the Undergraduate Level of a University Program: A Focus Group Approach,” Information Systems Education Journal, Vol. 12, Issue 4, pp. 40-48.

Merhout, J. W. and Havelka, D. 2008. "Information Technology Auditing: A Value-Added IT Governance Partnership between IT Management and Audit," The Communications of the Association for Information Systems: Vol. 23, Article 26. Available at: http://aisel.aisnet.org/cais/vol23/iss1/26

Merhout, J.W., Havelka, D., and Rajkumar, T.M., "Determining factors that lead students to study information systems using an alumni focus group,” 2016 Americas Conference on Information Systems, San Diego, CA, August 11-14, 2016.

Riemenschneider, C. K., Armstrong, D. J., and Moore, J. E. 2009. "GUEST EDITORIAL-Meeting the demand for IT workers: a call for research,” European Journal of Information Systems (2009) 18, 458-461.

Snyder, J. and Slauson, G. J. 2014. "Majoring in Information Systems: Reasons Why Students Select (or not) Information Systems as a Major, Information Systems Education Journal, Vol. 12, Issue 3, pp. 59-64.

Sutton, S.G., and Lampe, J.C. 1991. "A Framework for Evaluating Process Quality for Audit Engagements," Accounting and Business Research (21:83), pp. 275-288.

Trauth, E.M. (2012). “Are There Enough Seats for Women at the IT Table?” ACM Inroads, December 2012, v3n4, pp. 49-54.

Trauth, E.M., Quesenberry, J.L. \& Huang, H. 2009. "Retaining women in the U.S. IT workforce: theorizing the influence of organizational factors.” European Journal of Information Systems, 18, 476-497.

Tremblay, M. C, Hevner, A. R., and Berndt, D. J. 2010. "Focus Groups for Artifact Refinement and Evaluation in Design Research," Communications of the Association for Information Systems: Vol. 26, Article 27. Available at: http://aisel.aisnet.org/cais/vol26/iss1/27 